tensin system. Others give evidence that potassium might modify peripheral and central neural regulation of blood pressure. We can draw no conclusions from our study about the way that potassium acts. Nor is there a ready explanation for a possible mechanism of sodium-potassium interaction. Finally, there remains a possibility that potassium intake and the urinary sodium to potassium ratio are indicators of another, as yet unknown, determinant of blood pressure change in childhood rather than being direct causal factors in blood pressure regulation.

In conclusion, this study supports the view that dietary potassium and the dietary sodium to potassium ratio may be important in the early pathogenesis of hypertension. Possibly a sufficient intake of potassium or a reduction of the dietary sodium to potassium ratio in youth may prove to be beneficial in the early prevention of hypertension.

1 Hofman A, Grobbee DE, Schalekamp MADH, eds. The early pathogenisis of primary hypertension. Amsterdam: Elsevier, 1987.

2 Akinkugbe $O O$, Akinkugbe FM, Aveni $O$, et al. Biracial study of arterial pressures in the first and second decades of life. Br Med f 1977;i:1132-4.

3 Hofman A, Valkenburg HA. Determinants of change in blood pressure during childhood. Am f Epidemiol 1983;117:735-43.

4 Hofman A, Valkenburg HA. Maas J, Groustra FN. The natural history of blood pressure in children. Int $\mathcal{F}$ Epidemiol 1985;14:91-6.

5 LaBarthe DR, Morris DL, Freer BS. Blood pressure during growth and development. Ann Clin Res 1984;16 (suppl 4):35-43.

6 Simpson FO. Salt and hypertension: current data, attitudes, and policies. f Cardiovasc Pharmacol 1984:6: $44-9$

7 Grobbee DE, Bak AAA. Electrolyte intake and hypertension in children. In
Rettig R, Ganten D, Luft FC, eds. Salt and hypertension. Berlin: Springer Verlag, 1989

8 Intersalt Cooperative Research Group. Intersalt: an international study of electrolyte excretion and blood pressure. Results for 24 hour urinary sodium and potassium excretion. Br. Med f 1988;297:319-28.

9 Hofman A. Blood pressure in childhood: an epidemiologic approach to the aetiology of hypertension. 7 Hypertens 1984;2:323-8.

10 Khaw KT, Thom S. Randomized double-blind crossover trial of potassium on blood pressure in normal subjects. Lancet 1982;ii:1127-9.

11 Szklo M. Epidemiologic patterns of hlood pressure in children. Epidemiol Rez 1979;1:143-69.

12 Lauer RM, Burns TL, Clarke WR. Epidemiology of blood pressure in childhood. In: Hofman A, Grobbee DE, Schalekamp MADH, eds. The early childhood. In: Hofman A, Grobbee DE, Schalekamp MADH, ed
pathogenesis of primary hypertension. Amsterdam: Elsevier, 1987.

13 Liu K, Dyer AR, Cooper RS, Stamler R, Stamler J. Can overnight urine replace 24-hour urine collection to assess salt intake? Hypertension 1979;1 529-36

14 Knuiman JT, van Poppel G, Burema J, van der Heijden I, Hautvast GAJ Multiple overnight urine collections may be used for estimating the excretion of electrolytes and creatinine. Clin Chem 1988;34:135-8.

15 Lever AF, Beretta-Piccoli C, Brown JJ, Davis DL, Fraser R, Robertson JIS Sodium and potassium in essential hypertension. Br Med f 1981:283:463-7. 16 Grobbee DE, Hofman A. Does sodium restriction lower blood pressure? BrMed f 1986:293:27-9.

17 Hofman A, Hazebroek A, Valkenburg HA. A randomized trial of sodium intake and blood pressure in newborn infants. FAMA 1983;250:370-3.

18 Khaw KT, Barrett-Connor E. The association between blood pressure, age, and dietary sodium and porassium: a population study. Circulation 1988;
$77: 53-61$.

19 Frank GC, Bereson GS, Webher LS. Dietary studies and the relationship of diet to cardiovascular disease risk factor variables in 10 -year-old children. The Bogalusa heart study. Am $f$ Clin Nutr 1978;31:328-40.

20 Cooper R, Liu K. Trevisan M, Miller W, Stamler J. Urinary sodium excretion and blood pressure in children: absence of a reproducible association. Hypertension 1983;5:135-9.

21 Liu K, Cooper RS, Soltero I, Stamler J. Variability in 24-hour urine sodium excretion in children. Hypertension 1979;1:631-6.

22 Treasure J, Ploth D. Role of dietary potassium in the treatment of hypertension. Hypertension 1983;5:864-71.

Accepted 3 fanuary 1990)
Department of Public

Health Sciences, Bowman-

Gray School of Medicine,

Winston-Salem, North

Carolina 27103, United

States

Stephan Rössner, MD,

visiting professor

Carol L Taylor, MAS,

statistician

Robert P Byington, PHD,

assistant professor

Curt D Furberg, PHD,

chairman

\section{Correspondence to:}

Dr S Rössner, Obesity Unit,

Karolinska Hospital,

S-104 01 Stockholm,

Sweden.

Br Med f 1990;300:902-3

\title{
Long term propranolol treatment and changes in body weight after myocardial infarction
}

\author{
Stephan Rössner, Carol L Taylor, Robert P Byington, Curt D Furberg
}

\begin{abstract}
Objective-To determine the effect of long term propranolol treatment on body weight.

Design-Retrospective analysis of data from a placebo controlled randomised double blind clinical trial (the $\beta$ blocker heart attack trial).
\end{abstract}

Patients - 3837 Men and women randomised 5-21 days after an acute myocardial infarction to treatment with placebo or propranolol for up to 40 months. Patients were followed up at annual visits.

Main outcome measure-Changes in body weight.

Results - At the first annual visit patients treated with propranolol had gained more weight than those given placebo (mean weight gain $2.3 \mathrm{~kg} v 1.2 \mathrm{~kg}$ respectively, mean difference $1.2 \mathrm{~kg}(95 \%$ confidence interval 0.9 to 1.5 )). These group differences remained at the second and third annual visits. The difference in weight gain could not be explained by discrepancies in the use of diuretics or in physical activity and was similar in patients of both sexes and of all ages.

Conclusion-Long term $\beta$ blockade results in a sustained weight gain.

\section{Introduction}

Recently it has become increasingly clear that obesity is a multifactorial condition. Though the development of obesity implies at least a temporary positive energy balance, factors that explain why some people become overweight and others do not have been surprisingly difficult to identify. A recent study showing that large eaters in fact weighed less than small eaters has underscored the complexity of the problem.
As the autonomic system affects energy metabolism ${ }^{23}$ alterations in autonomic activity might be expected to promote obesity in some human subgroups. Despite numerous studies showing the effects of $\beta$ blockade on thermogenesis it has been argued that long term $\beta$ blockade does not result in weight gain in humans. This might be because small drug induced increases in weight over time are obscured by the continuous increase in body weight seen with age. We used data from the $\beta$ blocker heart attack trial to analyse retrospectively the effect of long term treatment with propranolol compared with placebo on body weight in patients who had had a myocardial infarction.

\section{Patients and methods}

A detailed description of the design of the $\beta$ blocker heart attack trial and its methods has been reported elsewhere. ${ }^{+}$In summary, 3837 men and women who had survived an acute myocardial infarction were randomised within five to 21 days after the infarction to treatment with propranolol or placebo. During an average follow up of 25 months mortality from all causes and fatal and non-fatal myocardial infarctions were significantly reduced.

We analysed height, body weight, and heart rate at baseline and after one, two, and three years of follow up from the trial database by sex, age, concomitant use of diuretics, and reported changes in physical activity. We used a multivariate repeated measures analysis of covariance that adjusted for age, sex, and use of diuretics to determine the possible effect of propranolol on body weight. ${ }^{5}$ As a large proportion of subjects were not followed up for two or three vears several estimation methods were applied, which produced the 
same results as analyses based on the patients with complete follow up data."

\section{Results}

At the start of the trial the mean age of the 3837 patients (602 women) was $55 \cdot 3$ years and the median body mass index $25.0 \mathrm{~kg} / \mathrm{m}^{2}$, the fifth and 95 th centiles being $19.9 \mathrm{~kg} / \mathrm{m}^{2}$ and $33.3 \mathrm{~kg} / \mathrm{m}^{2}$. The mean weight changes in all patients are summarised in the figure. In both groups there was an increase in weight after one year, when 1648 patients remained in the placebo group and 1679 in the propranolol group. In the placebo group the mean weight increased from $77.9 \mathrm{~kg}$ to $79.1 \mathrm{~kg}$ and in the propranolol group from $78.2 \mathrm{~kg}$ to $80.5 \mathrm{~kg}$, a mean difference of $1.2 \mathrm{~kg}$ with a $95 \%$ confidence interval of 0.9 to 1.5 . The corresponding figures at one year for both sexes were similar.

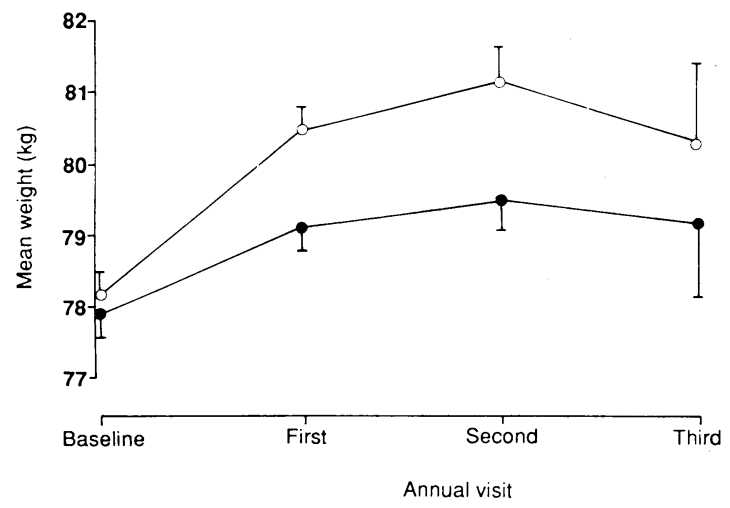

Changes in body weight in patients taking propranolol $\left(\mathrm{O}_{-}-\mathrm{O}\right)$ and placebo (- - over period of three years. Vertical bars show ISE

Between the first and second annual visit the mean body weight increased significantly in both groups; at this time 930 patients remained in the placebo group and 963 in the propranolol group. At the second annual follow up visit the mean gain in body weight from baseline was $1.6 \mathrm{~kg}$ in the placebo group and $3.0 \mathrm{~kg}$ in the propranolol group. This difference remained at the third annual follow up visit, when there were 155 patients in the placebo group and 156 in the propranolol group.

The pattern was essentially the same when the data were analysed by age $(<60$ and $\geqslant 60)$. At the second annual visit the 294 patients taking placebo who were aged $\geqslant 60$ had gained $1.4 \mathrm{~kg}$ in weight, whereas the corresponding figure for the 304 patients taking propranolol was $2 \cdot 1 \mathrm{~kg}$, a mean difference of $0.7 \mathrm{~kg}$ $(0 \cdot 4$ to $1 \cdot 0)$. In those aged $<60$ (588 patients taking placebo and 611 taking propranolol) the mean difference was $1 \cdot 1 \mathrm{~kg}(0 \cdot 8$ to $1 \cdot 4)$.

The percentage of patients using diuretics after one year was $26 \%(437 / 1679)$ in the propranolol group and $29 \%(478 / 1648)$ in the placebo group, but after two years 32\% (304/963) and 31\% (291/930) respectively were treated with diuretics; after three years the figures were $35 \%(55 / 156)$ in the propranolol group and $32 \%$ $(50 / 155)$ in the placebo group. The differences at two and three years were not statistically different. A multivariate analysis showed that the use of diuretics was not related to change in weight. Physical activity, as evaluated by subjective reports of activity, was similar in both groups throughout the study. At the first annual follow up visit $27 \%(456 / 1679)$ of patients taking propranolol and $21 \%(350 / 1648)$ taking placebo had gained more than $5 \mathrm{~kg}$ in weight.

\section{Discussion}

The mean body weight in many countries in the Western world increases steadily with age and then tends to fall again in the seventh decade of life. Minor changes in weight from other causes may therefore be overlooked unless placebo controlled data are available.

Our results show that during long term treatment with propranolol weight increased significantly and in addition to the increase attributable to aging. This increase remained when age, sex, and baseline weight were adjusted for. Our patients had survived a myocardial infarction, and we do not know to what extent our results can be extrapolated to other groups of patients taking $\beta$ blockers or $\beta$ adrenergic agents long term.

The fact that consistent findings were obtained in several subgroups indicates that the differences in weight reflect a true effect of propranolol. The mechanism of action remains unclear. In this study we were not able to determine which body tissues increased in weight. Fluid retention is not, however, an established side effect of treatment with $\beta$ blockers.

It could be argued that patients treated with placebo might require more diuretics for their ensuing cardiovascular problems. In the placebo group the proportion of diuretic users was slightly higher at the one year follow up visit, but this pattern was inconsistent $(+3.0 \%$ after one year, $-0.3 \%$ after two years, and $+2 \cdot 7 \%$ after three years) and seems too small to account for the systematic weight differences.

Patients taking $\beta$ blockers might be more capable of performing physical activity than patients taking placebo, but such increased energy expenditure would most likely have led to a lower weight in the patients taking propranolol, which suggests that the difference in weight was underestimated. Questionnaire data on reported physical activity, however, showed no difference between the groups at any time.

The mean increase in body weight that could be attributed to propranolol was moderate. In some patients, however, even such a moderate weight increase could be clinically important.

SR was awarded a visiting scholarship at Bowman-Gray School of Medicine to carry out this study.

I George V, Tremblay A, Despres JP, Leblanc C, Presusse L, Bouchard C Evidence for the existence of small and larger eaters of similar fat-free mas and activity level. Int 7 Obes 1989;13:43-54

2 Landsberg L, Young JB. The role of the sympatoadrenal system in modulating energy expenditure. Clinics in Endocrinology and Metabolism 1984;13:475-99.

3 Bray GA. Integration of energy intake and expenditure in animals and man: the autonomic and adrenal hypothesis. Clinics in Endocrinology and Metabolism 1984;13:521-46.

4 Bvington RP for the Beta-Blocker Heart Attack Trial Research Group. Beta blocker heart attack trial: design, methods and baseline results. Controlled Clin Trials 1984;5:382-437.

5 Jennich RF, Schluchter MD. Unbalanced repeated-measures models with structured covariance matrices. Biometrics 1986;42:805-20.

6 Little JA, Rubin DB. Siatistical analvsis with missing data. New York: Wiley,

(Accepted II Fanuary 1990) 